\title{
Modeling Response Incentive Effects in Dichotomous Choice Contingent Valuation Data
}

\author{
Anna Alberini; Barbara Kanninen; Richard T. Carson \\ Land Economics, Vol. 73, No. 3. (Aug., 1997), pp. 309-324.
}

Stable URL:

http://links.jstor.org/sici?sici=0023-7639\%28199708\%2973\%3A3\%3C309\%3AMRIEID\%3E2.0.CO\%3B2-2

Land Economics is currently published by University of Wisconsin Press.

Your use of the JSTOR archive indicates your acceptance of JSTOR's Terms and Conditions of Use, available at http://www.jstor.org/about/terms.html. JSTOR's Terms and Conditions of Use provides, in part, that unless you have obtained prior permission, you may not download an entire issue of a journal or multiple copies of articles, and you may use content in the JSTOR archive only for your personal, non-commercial use.

Please contact the publisher regarding any further use of this work. Publisher contact information may be obtained at http://www.jstor.org/journals/uwisc.html.

Each copy of any part of a JSTOR transmission must contain the same copyright notice that appears on the screen or printed page of such transmission.

The JSTOR Archive is a trusted digital repository providing for long-term preservation and access to leading academic journals and scholarly literature from around the world. The Archive is supported by libraries, scholarly societies, publishers, and foundations. It is an initiative of JSTOR, a not-for-profit organization with a mission to help the scholarly community take advantage of advances in technology. For more information regarding JSTOR, please contact support@jstor.org. 


\begin{abstract}
This paper introduces model specifications that can be used to explain response incentive effects that might occur with discrete response contingent valuation data when follow-up responses are collected. The models allow for possible random response shocks, structural shifts in willingness to pay between payment questions and heteroskedasticity between and within responses. Three well-known contingent valuation survey datasets that include follow-up payment questions are used to empirically test the models. (JEL C33, C35)
\end{abstract}

\section{INTRODUCTION}

Contingent valuation (CV) is a surveybased approach to measuring nonmarket values (Mitchell and Carson 1989; Bateman and Willis forthcoming). Participants in a CV exercise are given a scenario that describes a proposed policy that would alter environmental quality or the provision of a public good, and are asked to report information about their maximum willingness to pay (WTP) to secure such a change. In recent applications of the $\mathrm{CV}$ method, respondents have been assigned specific dollar amounts that they are told represents the cost of the proposed policy to their household and are asked whether they would vote for or against the plan at that cost. In the CV literature, models developed to explain these binary responses are often referred to as single-bounded models.

Information about WTP can be enhanced by taking repeated, binary choice observations on individual respondents' WTP amounts. Carson, Hanemann, and Mitchell (1986) first introduced the double-bounded approach within referendum CV surveys to refine the information about a respondent's WTP, and Hanemann, Loomis, and Kanninen (1991) showed the improvement in the statistical efficiency of the estimates brought about by the double-bounded follow-up question. In a typical double-bounded CV question the follow-up cost amount assigned to each respondent is dependent upon the response to the initial cost amount offered: if the initial response is positive, then the follow-up cost amount is greater than the initial cost amount and if the initial response is negative, the follow-up cost amount is less. Double-bounded models rely on the assumption that one WTP value drives a subject's responses to both payment questions.

Recently, some studies have found that the standard CV models do not adequately explain CV data. Langford (1994) detects the presence of overdispersion with $\mathrm{CV}$ data and suggests correcting for this problem by estimating a model that includes an overdispersion parameter (Williams 1982). Cameron and Quiggin (1994) suggest that the double-bounded model is inadequate for explaining the relationship between the responses to the initial and follow-up CV questions and introduce a bivariate probit specification which includes a parameter that represents the correlation between the two responses. Poe, Welsh, and Champ (1997) apply bivariate probit models to link the yes/no votes to two different proposed programs within the same survey instrument. In these examples, CV models are developed that include an additional parameter to increase the flexibility and improve the fit of the standard CV models. But these additional parameters are introduced as econometric, rather than structural, adaptations of the standard CV models and are not guided by an understanding of how sub-

The authors are, respectively, assistant professor in the Economics Department, University of Colorado, Boulder; assistant professor in the H.H. Humphrey School of Public Policy, University of Minnesota, Minneapolis; and professor in the Economics Department, University of California, San Diego. We thank two anonymous reviewers for their insightful comments and suggestions. 
jects form their responses to the payment questions.

This paper seeks to explain responses to discrete choice $\mathrm{CV}$ questions by considering structural adaptations to the standard double-bounded models that incorporate response incentive effects. We introduce model specifications that are consistent with several possible $\mathrm{CV}$ response incentives and empirically test them using three well-known dichotomous choice CV datasets that include follow-up questions. Previous research on response incentives in surveys with follow-up questions has explored the possibilities of yea-saying (Kanninen 1995), starting point effects (Herriges and Shogren 1996), and "ambivalence" (Opaluch and Segerson 1989; Ready, Whitehead, and Blomquist 1995). Our models explore the possibilities of random response "shocks," structural shifts in WTP, and heteroskedasticity between and within responses.

This paper is organized as follows: Section II describes our hypotheses about specific response incentive effects; Section III briefly discusses the three CV datasets that will be analyzed; Section IV presents model specifications and estimation results; and Section $\mathrm{V}$ provides concluding comments.

\section{CV RESPONSE INCENTIVE HYPOTHESES}

In this section, we outline our hypotheses about response incentive effects. We begin by describing a random effect interpretation of $\mathrm{CV}$ responses. This interpretation will be maintained while we investigate our other hypotheses. The latter include a structural shift in WTP between the first and second payment questions, plus several possible effects that generate heteroskedasticity between respondents and within subject responses between the initial and the follow-up payment question.

\section{Random Effect Models of WTP}

Random-effect models assume that the residual term of the variable under investigation can be broken down into two or more components. These components of error can be used to separate random shocks to the dependent variable from shocks that are randomly distributed over the population, but are common within the group to which an individual or experimental unit belongs, or common to a given individual over time. Random-effect models were introduced in econometrics to explain unobserved heterogeneity, whereby two individuals that share identical observed characteristics might still exhibit systematically different choices.

According to the random-effect model, each respondent bases both the initial and the follow-up questions on a WTP amount that has mean value equal to the respondent's true WTP; but the actual WTP amount used when responding to a particular payment question is subject to random error. The respondent might, for example, be unable to pinpoint an exact WTP figure for the good in question and might provide responses to the initial and follow-up questions that are, in fact, based on two different amounts. Since the respondent's mental behavior is unobservable and not responsive to any cues provided by the survey instrument or protocol, the difference in the WTP amounts used in formulating the two responses are attributed to a transitory error term or random response shock.

\section{Structural Shift in WTP}

The standard double-bounded specification is premised on the assumption that respondents base their answer to both the initial and follow-up vote questions on the same WTP amount. But the circumstances surrounding the two events differ in one important way: the implied information about the cost of the program is different for each question. The change in information may cause individual WTP amounts to systematically shift between the two responses, thus violating the standard assumption underlying the double-bounded model.

Empirical evidence from focus groups and verbatim responses to debriefing questions suggest that in some cases respondents effectively substitute the quality or quantity of 
the program being valued to a different level when moving from the first payment question to the follow-up (Carson et al. 1992). For example, many respondents who favor a project at the original cost have been found to refuse to pay a higher cost in the follow-up vote, even though their true WTP values might be large enough to warrant acceptance. This may be because the initial cost suggested makes them believe the government can deliver the good at that cost. The additional amount they are asked to pay is then expected to result in government waste. This is likely to be perceived as undesirable and hence the optimal strategic response may be to indicate a "no" vote to the follow-up vote question.

Furthermore, respondents who initially oppose a project might feel that a lesser contribution by taxpayers, as implied by the lower follow-up cost amount, would lower the likelihood that the government actually delivers the good, or result in the government providing only a pared-down version of the original program at the new, lower cost amount. If these arguments are correct, then in the follow-up vote some respondents are effectively substituting the program or policy described in the scenario with another program or policy package that has different characteristics, and are forming a new, systematically different WTP value that reflects the attributes of the new program.

\section{Heteroskedasticity Between and Within Responses}

Discrete choice models are often quite sensitive to the presence of heteroskedastic error terms (Gourieroux 1984). Betweenquestion heteroskedasticity affecting one subject's willingness to pay may arise if individuals become more focused on their preferences as the survey proceeds, or confused about how much they will have to pay or what they will actually get. Individuals may also react differently to the different offered cost amounts and their WTP values exhibit between-individual heteroskedasticity.

The two types of heteroskedasticity can be combined to imply that there is within-in- dividual heteroskedasticity (an individual exhibits different levels of variation in the two payment questions which offer different cost amounts) as well as between-individual heteroskedasticity (within the same payment question, different subjects are assigned different cost amounts, which result in different variances).

We propose a statistical model of heteroskedasticity to discriminate between two competing hypotheses about the effect of the cost amounts on the variance of the "transitory" component of WTP. ${ }^{2}$ The first hypothesis is that the closer the cost amount is to the respondent's WTP, the harder it is for the respondent to answer the payment question correctly, whereas it is much easier to give the correct answer when the cost amount is far from the WTP value. ${ }^{3}$ The other hypothesis contends that stated cost amounts that are "high" or "low" relative to

\footnotetext{
${ }^{1}$ In other words, if in the initial payment question the plan quantity (or quality) and its price are taken as exogenous by the respondent, the follow-up question may make quantity and/or price endogenous from the respondent's perspective. One approach that might avoid this problem would intentionally manipulate the good in the follow-up vote question so that the respondent is steered away from making the assumptions mentioned above. For instance, a subject who favors the project in the first payment question might be offered an improved version of the project in the follow-up question that would be at least as attractive as the initial good. Similarly, a subject who initially opposed the policy at the stated cost amount should be offered a scaled-down version of the project that costs less. A hedonic bivariate probit model for WTP could then be estimated which exploits the attributes of the goods and the relationship between the two projects being offered. Here, one needs to guard against interaction effects between the different projects.

${ }^{2}$ As is discussed below, we decompose the unexplained portion of willingness to pay into two components. One affects all observations contributed by the same subject, the other is "transitory," that is, a completely unpredictable white noise error.

${ }^{3} \mathrm{~A}$ similar effect might be noted if a subject is asked to reveal whether or not his/her annual income is more or less than a stated sum. If this sum is very large or very small relative to the subject's true income, it is easy for the subject to answer this question exactly, but more effort is required to answer the question exactly when the suggested sum is in the ballpark of the respondent's true income.
} 
the respondent's WTP amount may be deemed implausible by the respondent, thus affecting the credibility of the scenario. ${ }^{4}$ This "confuses" the respondent and increases the variance of WTP around the mean value. Clearly, both of these models presume that the variance of the transitory component of WTP is a function of the distance between WTP and the cost amount, and in fact the statistical test we suggest to discriminate between the two competing hypotheses is based on the sign of the estimated coefficient on a function of the distance between WTP and the cost amount provided.

The formal models associated with the hypotheses outlined in this section are presented in Section IV. It should be noted that we generally cannot distinguish among these models in a statistical sense. Instead, for any specific example, we must rely on our understanding of the incentive structures presented in any particular CV survey to determine the appropriate model specification.

\section{THE DATA}

In this section, we describe the three CV datasets we analyze in the remainder of the paper, the San Joaquin Valley wetlands study (Hanemann, Loomis, and Kanninen 1991), the study on the Kakadu Conservation Zone in Australia (Carson, Wilks, and Imber 1994), and the survey to estimate the loss of passive-use values for Prince William Sound resulting from the Exxon-Valdez oil spill of 1989 (Carson et al. 1992).

The San Joaquin Valley data were collected via a mail/telephone survey of California residents conducted in May 1989 for the Interagency San Joaquin Valley Drainage Program. Sixty-three percent of those respondents who were initially contacted over the telephone by random digit dialing accepted to participate in the survey, and about 95 percent of them completed the final interviews. The survey focused on WTP for protecting wildlife and wetlands habitat in California's San Joaquin Valley. It asked respondents to consider five environmental programs. Here, we focus on one program which would improve wetlands habitat above current levels. The exact payment question was: "If the wetlands habitat and wildlife improvement program were the only program you had an opportunity to vote on, and this improvement cost every household in California \$_ each year in additional taxes, would you vote for it?" Initial cost amounts were $\$ 55,65,75,85,125,140,170$, 210, and 250. Follow-up cost amounts were $\$ 25,30,40,65,75,80$, and 125 when the initial response was a "no," and $\$ 110,125$, 170,250 , and 375 when the initial response was a "yes." Forty percent of the respondents answered "yes" to both payment questions, 24 percent answered positively to the initial payment question and negatively to the follow-up, 18 percent answered "no" and "yes" (in order), and 18 percent gave two "no" responses.

The Kakadu data were collected via an in-person survey of a sample of Australian residents. This survey (sponsored by the Australian Resource Assessment Commission) was conducted in April 1990 and resulted in a response rate of about 62 percent. The purpose of the study was to estimate the economic benefits of preserving the Kakadu Conservation Zone. Two scenarios were developed - a major impact scenario and a minor impact scenario. Both described four types of environmental impacts: (1) mine related traffic, (2) chemicals used to extract minerals, (3) mine process water and waste rock material, and (4) possible injury to the environment and wildlife. The major impact scenario described a realistic worst case and the minor impact scenario primarily described unavoidable onsite effects of mining in the zone. Here, we

\footnotetext{
${ }^{4}$ In effect, we are using an estimate of expected WTP as a proxy for the more appropriate variable, expected cost. While this may be reasonable in many cases, this proxy is likely to have bad properties in situations where the respondent does not care about whether the good is provided or when the respondent has a clear perception of the likely cost of providing the good, which is unrelated to the respondent's WTP for it.
} 
focus on the minor impact scenario. The payment vehicle was a reduction in annual take-home pay. Initial cost amounts were $\mathrm{A} \$ 5,20,50$, and 100 and follow-up cost amounts were $\mathrm{A} \$ 2,5,20$, and 50 if the initial response was a "no," and $A \$ 20,50$, 100 , and 250 if the initial response was a "yes." As shown in Table 1, 47 percent of the respondents provided two positive responses and 40 percent gave two negative responses, whereas approximately 8 and 5 percent of the respondents fell in the ("yes," "no") and ("no," "yes") response categories, respectively.

The Alaska data were collected via an in-person survey of a representative sample of United States residents conducted in spring and summer 1992 for the State of Alaska, for an overall response rate of about 75 percent. The survey was designed to measure the loss of passive use values arising from injuries to natural resources caused by the Exxon Valdez oil spill. The willingness-to-pay question asked how the respondent would vote on a plan to prevent an- other oil spill similar in magnitude to the Exxon Valdez spill.

After describing in detail how tankers would be escorted out of Valdez into Prince William Sound and how an emergency response would be enacted in the event of a spill, the survey instrument specified that oil companies would be charged a one-time tax that would reduce their profits, and households would pay a one-time charge that would be added to their federal taxes in the first year of the plan. Respondents were then reminded of possible arguments for voting against or in favor of the plan, and were told that "At present, government officials estimate the program would cost your household a total of \$X. You would pay this in a special one time charge in addition to your regular federal taxes. This money would only be used for the program to prevent damage from another oil spill in Prince William Sound." This was followed by the vote question: "If the program cost your household a total of $\$ \mathrm{X}$, would you vote for the program? Or against the program?"

TABLE 1

Number of Responses in EACH CATEgory ReSPONSE by OFFER AMOUNT FOR THE THREE STUDIES

\begin{tabular}{lrccc}
\hline \hline & NO, NO & NO, YES & YES, NO & YES, YES \\
\hline \hline Initial Payment Amount & & & & \\
San Joaquin Valley Study $(n=548)$ & 5 & 5 & 12 & 10 \\
55 & 3 & 4 & 6 & 16 \\
65 & 7 & 3 & 12 & 10 \\
75 & 9 & 11 & 21 & 48 \\
85 & 25 & 24 & 25 & 49 \\
125 & 8 & 14 & 20 & 18 \\
140 & 14 & 20 & 18 & 36 \\
170 & 22 & 17 & 11 & 14 \\
210 & 10 & 7 & 5 & 9 \\
250 & & & & \\
& & & & \\
Alaska Study $(n=1,043)$ & 78 & 8 & 59 & 119 \\
10 & 98 & 31 & 69 & 69 \\
30 & 101 & 25 & 74 & 55 \\
60 & 139 & 30 & 53 & 35 \\
120 & & & & \\
& & & & \\
Kakadu Study $(n=1,088)$ & 103 & 7 & 19 & 164 \\
5 & 103 & 11 & 16 & 158 \\
20 & 110 & 18 & 28 & 99 \\
50 & 125 & 19 & 21 & 87 \\
100 & & & & \\
\hline
\end{tabular}


Initial cost amounts were $\$ 10,30,60$, and 120. Follow-up cost amounts were $\$ 5,10,30$, and 60 if the initial response was a "no," and $\$ 30,60,120$, and 250 if the initial response was a "yes." 5 Twenty-seven, 25, 9, and 39 percent of the respondents provided (“yes," “yes”), (“yes," “no”), (“no," “yes”) and ("no," "no") responses, respectively.

The San Joaquin Valley study differs from the other two surveys in that it presents multiple scenarios (as well as multiple payment questions within each scenario). The three studies also differ in important ways with respect to the provision of the plan, although in all three of them the scenario states that the government takes an active role in providing the environmental/resource plan. In the Kakadu survey, the government will have to increase taxes to replace the lost royalties from mining if conservation is chosen over mining exploitation. Because of the uncertainty associated with the outcome of the mining process, it is possible that respondents may have treated the cost to their households specified in the survey questionnaire simply as indicative, but not necessarily binding, and might have been more accepting of the revised cost estimates of the follow-up questions. In contrast, the Alaska survey detailed a very specific plan (escort ships, highly trained spill containment crews) for which the government may have been expected to have exact cost estimates. Hence, respondents may have been less accepting of the revised cost estimates in the follow-up question.

Finally, Alaska and Kakadu studies entail only four bid sets and are thus in sharp contrast with the San Joaquin Valley survey, which has nine bid sets. What is even more important than the number of bid sets used, however, is where along the WTP distribution the bid points are located. For example, all but two initial bids in the San Joaquin Valley study were located to the right of the median WTP value. This might explain why the estimated WTP distribution curve is rather flat and the confidence interval around mean WTP large. The percent of "yes" responses after the first round of pay- ment questions ranged between 43 and 62 for the Kakadu data, and between 33 and 68 for the Alaska survey.

\section{MODELING AND TESTING CV RESPONSE INCENTIVES}

The utility-theoretic approach to modeling individual, binary choice behavior in response to CV questions was developed by Hanemann (1984) and extended to the double-bounded case by Hanemann, Loomis, and Kanninen (1991). ${ }^{6}$ The approach requires the specification of the CV respondents' underlying utility functions which are estimated using a random utility framework. The log-likelihood for a given set of CV responses is a function of the difference between the systematic components of the utility functions with and without the proposed program and cost amount. WTP can be estimated as a function of the maximum likelihood estimates of the underlying utility parameters.

Cameron (1988) introduced an alternative approach to modeling $\mathrm{CV}$ data that bypasses the underlying utility model and estimates the parameters of the latent WTP distribution directly. This approach has the advantage of providing parameter estimates that are easy to interpret as components of WTP (as opposed to utility) and McConnell (1990) has shown that it is dual to the Hanemann approach. For simplicity of notation

\footnotetext{
${ }^{5}$ In the San Joaquin Valley and the Kakadu surveys the follow-up amounts were one-half or double the initial payment amounts. In the Alaska study, the data coming from three pilot studies were used to estimate the distribution of willingness to pay conditional on a set of regressors (income, age, education, etc.). The initial payment amounts were the quintiles of the fitted distribution of WTP based on the sample averages of the regressors. The follow-up amounts were the median values of the same distribution truncated from below and above, respectively, at the initial payment amounts. Alberini (1995a) investigates the performance of both the former and the latter type of statistical designs using simulations.

${ }^{6}$ See Hanemann and Kanninen (forthcoming) for further discussion of these models including utility-theoretic restrictions, model specifications, and statistical properties of estimators.
} 
and ease of exposition, we adopt the Cameron approach in this paper.

\section{Checking the Fit of Double-bounded Models}

Suppose that latent WTP can be expressed as $W T P_{i}=x_{i} \beta+\varepsilon_{i}$, where $x_{i}$ is a $1 \times k$ vector of regressors and $\varepsilon_{i}$ is an independent error term with mean zero and variance $\sigma^{2}$. If $F$ is the cdf of WTP, the log likelihood function for the double-bounded model is:

$$
\begin{aligned}
\log L_{D B}=\sum_{i=1}^{n} \log [ & F\left(c_{i}^{U} ; x_{i}, \beta, \sigma\right) \\
- & \left.F\left(c_{i}^{L} ; x_{i}, \beta, \sigma\right)\right],
\end{aligned}
$$

where $c_{i}^{U}$ and $c_{i}^{L}$ are the upper and lower bounds of the interval around WTP.

Table 2 reports the estimates obtained from fitting double-bounded models without covariates to the data from our three CV surveys. Because individual-specific covariates are neglected in the models of Table 2, making the data effectively grouped by the cost amounts assigned to the respondents, we can use a variant of the residual $d e$ viance (Cox and Snell 1989) as a diagnostic test of the adequacy of the double-bounded models. ${ }^{?}$

For the San Joaquin Valley and the Kakadu CV survey data, we fitted doublebounded models based on the assumption of normal WTP variables and obtained deviance values of 19.72 and 3.86 , respectively. The former exceeds the 5 percent critical level of the chi square with $(9-2)=7$ degrees of freedom, indicating the presence of a phenomenon termed overdispersion, which occurs when the expected value of the deviance is greater than $(k-p), k$ being the number of different cost amounts covered in the survey and $p$ being the number of parameters in the model (Collett 1991). The deviance value for the Kakadu study, 3.86, is well within the acceptance region of the chi square with two degrees of freedom. For the Alaska CV survey data we assumed that WTP is a log normal and calculated the deviance value at 43.14, which exceeds the 5 percent critical level for a chi square with $(4-2)=2$ degrees of freedom, indicating the presence of overdispersion.

The statistical literature identifies several possible causes for overdispersion: relevant regressors may have been omitted, the distributional assumption for the latent variable may be inadequate, heteroskedasticity may exist, and-unbeknownst to the researcher-experimental conditions may have changed (Collett 1991). The following models incorporate our specific hypotheses on respondents' behavior to address these possibilities.

\section{Random-effect Models of WTP}

A random-effect representation of $\mathrm{CV}$ survey data might assume that the latent variable, WTP, is comprised of two parts, a component which is permanent over repeated questioning, and a transitory component that is associated with the particular payment question. This model is essentially a variant of a panel data model with random

\footnotetext{
${ }^{7}$ The deviance is defined as $D=-2 \cdot\left[\log L_{\hat{\theta}}-\right.$
} $\log L]$. The first term in brackets is $\log L_{\hat{\theta}}=\sum_{j=1}^{k}\left[r_{j}\right.$. $\left.\log \pi_{j}^{\text {yes }}+\left(n_{j}-r_{j}\right) \cdot \log \left(1-\pi_{j}^{\text {yes }}\right)\right]$, the parametric $\log$ likelihood function of the single-bounded model, where $r_{j}$ is the count of "yes" responses to the $j$ th cost amount assigned with the initial payment question, and $\pi_{j}^{\text {yes }}=F\left(\left(\operatorname{cost}_{j}-\hat{\mu}\right) / \hat{\sigma}\right)$ is the fitted probability of a positive response to the $j$ th cost amount. The second term in brackets in the expression for $D$ is $\log L=$ $\sum_{j=1}^{k}\left[r_{j} \cdot \log \left(r_{j} / n_{j}\right)+\left(n_{j}-r_{j}\right) \cdot \log \left(1-r_{j} / n_{j}\right)\right]$, a semiparametric log likelihood function that simply approximates the probabilities of each type of response with the observed sample frequencies of "yes" and "no" responses in each group. The first term of the deviance is usually calculated at the single-bounded model estimates. However, if the WTP model is correctly specified and WTP is unchanged between the payment questions, as is assumed by the double-bounded model, the double-bounded estimates should be close to the single-bounded estimates, and could be substituted for the latter when computing the deviance. Under the null hypothesis that the model of WTP is correctly specified, the deviance is distributed as a chi square with $(k-p)$ degrees of freedom, where $k$ is the number of different cost amounts covered in the survey and $p$ is the number of parameters specified by the model. 
TABLE 2

RANDOM-EFFECT AND DOUBLE-BOUNDED MODELS OF WTP FROM SELECTED CV SURVEYS

\begin{tabular}{|c|c|c|}
\hline Double-bounded Model* & Random-effect Model & \\
\hline \multicolumn{3}{|c|}{ San Joaquin Valley Wetlands Improvement CV Survey (sample size: 548 ) } \\
\hline$\mu \quad \begin{array}{ll}175.06 \\
(25.67)\end{array}$ & $\begin{array}{ll}\mu & 232.09 \\
& (8.35)\end{array}$ & \\
\hline $\begin{array}{ll}\sigma & 140.59 \\
& (19.39)\end{array}$ & $\begin{array}{ll}\sigma_{v} & 228.10 \\
& (4.99)\end{array}$ & \\
\hline & $\begin{array}{ll}\sigma_{\varepsilon} & 284.29 \\
& (3.25)\end{array}$ & $\begin{array}{c}\rho=0.3896 \\
(4.33)\end{array}$ \\
\hline $\log L-766.81$ & $\log L-727.44$ & \\
\hline \multicolumn{3}{|c|}{ Alaska Oil Spill CV Survey (sample size: 1,043 ) } \\
\hline $\begin{array}{ll}\mu & 3.364 \\
& (48.06)\end{array}$ & $\begin{array}{l}3.075 \\
(20.50)\end{array}$ & \\
\hline $\begin{array}{ll}\sigma & 2.003 \\
& (25.03)\end{array}$ & $\begin{array}{ll}\sigma_{v} & 2.989 \\
& (8.30)\end{array}$ & \\
\hline & $\begin{array}{ll}\sigma_{\varepsilon} & 2.028 \\
& (5.07)\end{array}$ & $\begin{array}{c}\rho=0.6847 \\
(13.69)\end{array}$ \\
\hline $\log L-1,373.34$ & $\log L-1,347.84$ & \\
\hline Implied Median WTP & Implied Median WTP & \\
\hline $\begin{array}{l}28.90 \\
(14.10)\end{array}$ & $\begin{array}{l}21.65 \\
(7.03)\end{array}$ & \\
\hline \multicolumn{3}{|c|}{ Kakadu Conservation Zone CV Survey (Minor Impact) (sample size: 1,088 ) } \\
\hline $\begin{array}{ll}\mu & 76.25 \\
& (9.27)\end{array}$ & $\mu \quad \begin{array}{ll}87.16 \\
(5.06)\end{array}$ & \\
\hline $\begin{array}{ll}\sigma & 265.18 \\
& (19.21)\end{array}$ & $\begin{array}{ll}\sigma_{v} & 446.93 \\
& (5.77)\end{array}$ & \\
\hline & $\begin{array}{ll}\sigma_{\varepsilon} & 79.40 \\
& (3.35)\end{array}$ & $\begin{array}{c}\rho=0.9694 \\
(96.94)\end{array}$ \\
\hline $\log L-1,179.61$ & $\log L-1,154.10$ & \\
\hline
\end{tabular}

Note: $t$-statistics are in parentheses.

* In the double-bounded model the correlation coefficient is constrained to be equal to one. $\mu$ is the mean/median of WTP and $\sigma$ is the standard deviation of WTP in the San Joaquin and the Kakadu studies, and of log WTP in the Alaska study.

effects (Hsiao 1986) and can be written:

$$
\left\{\begin{array}{l}
W T P_{1 i}=W T P_{i}^{*}+\varepsilon_{1 i} \\
W T P_{2 i}=W T P_{i}^{*}+\varepsilon_{2 i}
\end{array}\right.
$$

where the subscript $i$ indexes the individual respondent and the $\varepsilon$ 's are the transitory components occurring due to random response shocks. WTP*, the permanent component of WTP, can be further broken down: $W T P_{i}^{*}=\mu_{i}+v_{i}$, with $\mu_{i}=x_{i} \beta$. $\nu_{i}$ represents the part of WTP that is due to unobservable characteristics of individual $i$. This error component varies with the individual, but remains fixed over the individual's responses to different payment questions, thus introducing correlation between the underlying WTP amounts. ${ }^{8}$ Neglecting the unobserved individual heterogeneity brought about by this component can result in inconsistent estimates of the model coefficients (Hsiao 1986).

An important feature of the random-effect model is that this specification allows the initial and follow-up responses to be

\footnotetext{
${ }^{8}$ The error-component model of WTP is essentially analogous to a panel model of income that obtains two measurements of income from the same individual one year apart. The portion in parentheses would be permanent income (which is here assumed constant over time for the sake of simplicity) while the $\varepsilon$ 's would be the transitory shocks.
} 
based on two, possibly different, WTP values. In equations [2], the difference between the first and the second WTP values is, of course, completely driven by the random response shocks, $\varepsilon$ 's, because the permanent component of WTP does not change between payment questions. Unfortunately, in practice it is impossible to determine whether or not an individual was using the same WTP value when responding to the two questions because the particular structure of the follow-up questions prevents observing an individual's revisions of the WTP values between the vote questions. Another important feature of the two-equation random-effect model [2] is that, if appropriate assumptions are made about the covariance structure of $\varepsilon$ and $\nu$, the variances of the error components $\varepsilon$ and $v$ are identified. ${ }^{9}$

While in principle an error-component model can be conceived given any distributions of $v$ and $\varepsilon$, in the remainder of this paper the underlying distributions of these components are assumed to be normal for ease of computation and convenience. Following the standard assumptions in the econometric modeling literature, the two transitory components, $\varepsilon_{1}$ and $\varepsilon_{2}$, are defined so as to be independent of each other and of the permanent idiosyncratic term $v$ (Hsiao 1986). ${ }^{10}$ The variance of each WTP variable is thus the sum of the variances of the permanent and transitory components: $V\left(W T P_{i t}\right)=\sigma_{v}^{2}+\sigma_{\varepsilon_{i t}}^{2}$, with $t=1,2$ indexing the payment questions and $i=1,2, \ldots, n$ indexing the individuals. The permanent component makes the two WTP variables positively correlated, the covariance between $W T P_{1}$ and $W T P_{2}$ being exactly $\sigma_{v}^{2}$. The correlation coefficient, $\rho$, between $W T P_{1}$ and $W T P_{2}$, which is equal to $\sigma_{v}^{2} /\left[\left(\sigma_{v}^{2}+\right.\right.$ $\left.\left.\sigma_{\varepsilon_{i 1}}^{2}\right)\left(\sigma_{v}^{2}+\sigma_{\varepsilon_{i 2}}^{2}\right)\right]^{1 / 2}$, is low if the variance of the transitory component is large relative to the variance of the permanent component and approaches one when the variance of the permanent component is extremely large relative to those of the transitory components. ${ }^{11}$ In the limit, the double-bounded model, which assumes that the first and second individual WTP amounts are identical, is obtained as a special case of a ran- dom-effect model where the variance from the transitory component is negligible relative to that of the permanent component, making the coefficient of correlation $\rho$ between the two WTPs equal to one.

\section{Estimation of Random-effect Models}

When the two error components $\nu$ and $\varepsilon$ are assumed to be normally distributed, the random-effect model [2] is estimated as a bivariate probit model that allows for a free correlation coefficient (Chamberlain 1980; Maddala 1983). The log likelihood function of a bivariate probit model is:

$$
\begin{aligned}
\log L_{B P}= & \sum_{i=1}^{n}\left(1-y_{i 1}\right) \cdot\left(1-y_{i 2}\right) \cdot \pi_{i}^{N N} \\
& +\left(1-y_{i 1}\right) \cdot y_{i 2} \cdot \pi_{i}^{N Y} \\
& +y_{i 1} \cdot\left(1-y_{i 2}\right) \cdot \pi_{i}^{Y N}+y_{i 1} \cdot y_{i 2} \cdot \pi_{i}^{Y Y}
\end{aligned}
$$

where $y_{i 1}$ is a dummy variable that takes on a value of one if the response to the initial payment question was a "yes," and zero otherwise, and $y_{i 2}$ is also a dummy variable that takes on a value of one if the response to the follow-up question was a "yes," and zero otherwise. $\pi_{i}^{N N}, \pi_{i}^{N Y}, \pi_{i}^{Y N}$, and $\pi_{i}^{Y Y}$, the probabilities of each pair of responses, are calculated from the bivariate normal cdf $\Phi(\cdot, \cdot, \rho)$ as $\pi_{i}^{N N}=\Phi\left(z_{i 1}, z_{i 2}, \rho\right), \pi_{i}^{N Y}=$ $\Phi\left(z_{i 1}\right)-\Phi\left(z_{i 1}, z_{i 2}, \rho\right), \pi_{i}^{Y N}=\Phi\left(z_{i 2}\right)-$ $\Phi\left(z_{i 1}, z_{i 2}, \rho\right)$, and $\pi_{i}^{N Y}=1-\Phi\left(z_{i 1}\right)-$ $\Phi\left(z_{i 2}\right)+\Phi\left(z_{i 1}, z_{i 2}, \rho\right)$, where $\rho$ is the correlation coefficient between the two WTP

\footnotetext{
${ }^{9}$ In contrast, if a random-effect model is used, but only one equation can be specified and estimated (as would occur if the discrete choice CV survey is implemented without follow-ups), it is not possible to identify the components of the variance of WTP.

${ }^{10}$ This assumption allows identification of the two components of variance, $\sigma_{v}^{2}$ and $\sigma_{\varepsilon_{\lambda t}}^{2}$.

${ }_{11}$ The error-component model is easily generalized to the case with $T>2$ payment questions. Each latent WTP value is expressed as $W T P_{i t}=W T P_{i}^{*}+\varepsilon_{i t}$, with $W T P_{i}^{*}=x_{i} \beta+v_{i}$. The assumption of normality of the error components $\nu$ and $\varepsilon$ results in the vector of WTPs being distributed as a multivariate normal.
} 
amounts, $z_{i 1}=\left(c_{i 1}-x_{i} \beta\right) / \sigma, z_{i 2}=\left(c_{i 2}-\right.$ $\left.x_{i} \beta\right) / \sigma, c_{i 1}$ and $c_{i 2}$ are the cost amounts assigned to the respondent in the first and second payment question, respectively, $\sigma$ is the standard deviation of the latent WTPs, and $\Phi(\cdot)$ is the univariate standard normal cdf. The bivariate probit model was first suggested for use with data from discrete choice CV surveys with a follow-up by Cameron and Quiggin (1994).

Table 2 presents random-effect models estimated using the three CV examples. This table confirms the notion that a high correlation coefficient means that the variance of the permanent component is large relative to the variance of the transitory term, whereas a lower correlation coefficient implies the opposite relationship between the variances of these components.

The table shows that there are marked differences between the estimates of mean WTP from random-effect and standard double-bounded models when the variance of the transitory component of error is large, and, as a consequence, $\rho$ is low. Such is the case, for instance, with the San Joaquin Valley study, in which the correlation coefficient between the two WTP responses is only 0.39 and the difference between the double-bounded and the random-effect model estimates of mean WTP is about \$57. For comparison, with the Kakadu survey data, which exhibit a correlation coefficient of about 0.96 , the spread between mean WTP estimates is only A $\$ 11$, and the random-effect model estimate of WTP falls well within the 95 percent confidence interval around the double-bounded estimate. ${ }^{12}$ The high variance of the transitory component of willingness to pay noted in the San Joaquin study might well be the effect of the numerous scenarios and the multiple payment questions for each program, which may have impaired the respondents' ability to focus on the good being valued.

In all cases, however, the double-bounded estimates have much lower standard errors than the random-effect model estimates. An intuitive explanation for this finding is that, when the double-bounded model assumption that $\rho=1$ is relaxed, the initial and the follow-up responses only provide a sequence of two single-bounded intervals around the two WTP values, which are more or less correlated depending on the contribution of the permanent component relative to the transitory error components. ${ }^{13}$

\section{Structural Shift of WTP}

The random-effect model presented above can be modified to account for a shift in WTP as follows:

$$
\left\{\begin{array}{l}
W T P_{i 1}=W T P_{i}^{*}+\varepsilon_{i 1} \\
W T P_{i 2}=W T P_{i}^{*}+\delta_{i}+\varepsilon_{i 2}
\end{array}\right.
$$

where $\delta$ represents the structural shift in the WTP amount and is essentially the coefficient on a dummy variable representing the second payment question. $\delta$ could also

\footnotetext{
${ }^{12}$ The double-bounded estimates are also more efficient than the error-component estimates, which suggests that in many situations double-bounded models may still be preferred to bivariate probit models because of their superiority in terms of the mean squared errors of the WTP estimates, even though the error-component representation is the correct statistical framework (Alberini 1995b). Unfortunately, even after a random-effect model has been fitted, it is not possible to judge whether the fit has been improved by much, as the distribution of the deviance for a model that includes random effects is unknown (Collett 1991). We used the hessian of the log likelihood to compute the standard errors of the estimates, but a slightly different formula involving both the hessian (denoted as $F$ ) and the matrix of the outer products of the first derivatives of the $\log$ likelihood (denoted as $V$ ) could be used to produce misspecification-robust standard errors if the data are not well approximated by a normal distribution. The robust covariance matrix of the estimates is $F^{-1} V F^{-1}$. The estimates of the coefficients based on the assumption of a normal WTP variable remain consistent even if the true distribution is not a normal, as long as the true distribution belongs to the exponential family of distributions (Fahrmeir and Tutz 1994).

${ }^{13}$ We note here that it is not easily possible to discriminate between the fit of the double-bounded model and the random-effect model based on the respective $\log$ likelihood values. Although the doublebounded model is a limiting case of the random-effect specification for $\rho=1$, the likelihood ratio test and the Wald test for $\rho=1$ cannot be used for model selection purposes because their asymptotic distribution under the null that $\rho=1$, a value on the boundary of the parameter space, is not known (Alberini 1995b).
} 
be a function of additional explanatory variables including the cost amount or the change in cost amounts (Cameron and Quiggin 1994).

Results with the parameter $\delta$ included are presented in Table 3. Interestingly, in all three cases $\delta$ is negative. With the data from the Kakadu and San Joaquin Valley studies, $\delta$ is not significantly different from zero at conventional confidence levels. However, the data from the Alaska study does exhibit a significant downward shift in median WTP between the initial vote response $(\exp (3.75)=\$ 42.69)$ and the followup $(\exp (2.68)=\$ 13.54)$. A standard likelihood ratio test finds that the model is a significant improvement over the randomeffect model presented in Table 2.

\section{Between and Within Response Heteroskedasticity}

Because the respondent's WTP value cannot be observed, in order to write out an estimable model incorporating our structure for heteroskedasticity we replace the assumptions suggested by our competing models about the distance between WTP and the cost amount with the same assumptions about the distance between the systematic part of WTP $\left(\mu_{i}\right)$ and the cost. For the sake of illustration and in order to keep our models manageable, we also assume here that the systematic part of WTP is constant across equations $\left(\delta_{i}=0\right)$. Our general error-component model is completed by the heteroskedasticity structure $\sigma_{\varepsilon_{i t}}=\exp \left(\alpha_{0}+\right.$ $\left.\alpha_{1 t} \cdot\left(\mu_{i}-\operatorname{cost}_{i t}\right)^{2}\right)$, where $i$ indexes the individual sample unit and $t$ indexes the question, suggesting that the proximity of the cost amount to the average WTP of people with characteristics similar to their own affects peoples' abilities to respond consistently to the payment question. This general model also allows for the dispersion of WTP to be affected by the respective cost amount to an extent that can change from the first vote to the second. The standard deviation of the transitory component is a function of the squared distance between the current cost amount (for each question) and average WTP, hereafter referred to as the "cost distance."
Our competing hypotheses of heteroskedasticity can, therefore, be easily tested using the signs of the $\alpha_{1 t}$ 's. If respondents get confused by costs that are excessively high or low relative to the systematic part of WTP, $\alpha_{1}>0$, whereas if it is harder for the respondent to answer correctly when the project cost gets close to the average WTP of people with similar characteristics, then $\alpha_{1}<0$.

We estimate the models with heteroskedasticity both with and without covariates for the San Joaquin Valley and the Kakadu data, but only without covariates for the Alaska data (since covariates are not publicly available at this time). By including covariates in these models we are able to obtain more precise estimates of the difference between cost and respondents' systematic WTP amounts for use in the heteroskedastic variance terms. We discuss the model results without covariates only in the case where the results are different between the two models.

The most general version of our model of heteroskedasticity is reported in the third column of Tables 4-6 for our three datasets. The second column reports a restricted version of it that still allows for the dispersion parameters to be determined by the respective cost amount, but constrains the responsiveness to the cost amount to be identical across votes $\left(\alpha_{11}=\alpha_{12}\right)$. We also report the basic error-component model (first column) which is derived by setting $\alpha_{11}=\alpha_{12}$ to zero. All of these variants of the heteroskedasticity model allow for identification of how much of the variance of WTP values is due to the permanent component of WTP and how much is due to the transitory component.

Table 4 reports the estimation results from the San Joaquin Valley survey. When a model with a single coefficient on the cost distance $\left(\alpha_{1} \equiv \alpha_{11}=\alpha_{12}\right)$ is estimated, this parameter is found to be positive but insignificant, indicating that this dataset does not reveal any detectable relationship between the cost distance and response confusion. The model that allows the effect of cost distance to vary between the first and second questions also obtains positive but 
TABLE 3

RANDOM-EFFECT MODEL WITH SHIFT

\begin{tabular}{lccc}
\hline \hline Parameter & $\begin{array}{c}\text { San Joaquin Valley } \\
\text { Wetlands Improvement } \\
\text { CV Survey }\end{array}$ & $\begin{array}{c}\text { Alaska Oil Spill CV } \\
\text { Survey* }\end{array}$ & $\begin{array}{c}\text { Kakadu Conservation } \\
\text { Zone CV Survey } \\
\text { (Minor Impact) }\end{array}$ \\
\hline$\mu$ & 250.74 & 3.7543 & 96.22 \\
$\delta$ & $(6.43)$ & $(28.88)$ & $(4.55)$ \\
& -29.13 & -1.1494 & -12.55 \\
$\sigma$ & $(-0.97)$ & $(-5.22)$ & $(-1.00)$ \\
$\rho$ & 380.09 & 3.3278 & 479.40 \\
Sample size & $(3.69)$ & $(7.56)$ & $(5.05)$ \\
Log $L$ & 0.3836 & 0.7527 & 0.9588 \\
& $(4.26)$ & $(18.81)$ & $(95.88)$ \\
\hline
\end{tabular}

Note: $t$-statistics are in parentheses.

${ }^{*}$ For the Alaska CV survey data, Median WTP is $\exp (\mu)$.

TABLE 4

Heteroskedastic Random-efFect Model with Covariates: San Joaquin Valley CV SuRVey

\begin{tabular}{|c|c|c|c|c|c|}
\hline \multirow{2}{*}{$\begin{array}{l}\text { Variable / } \\
\text { Parameter }\end{array}$} & \multirow[b]{2}{*}{ Description of Variable } & \multirow{2}{*}{$\begin{array}{l}\text { Sample } \\
\text { Mean }\end{array}$} & $\begin{array}{c}\text { Basic Error- } \\
\text { Component Model }\end{array}$ & $\begin{array}{l}\text { Error-Component } \\
\text { Model with } \\
\text { Heteroskedasticity } \\
\text { I }\end{array}$ & $\begin{array}{l}\text { Error-Component } \\
\text { Model with } \\
\text { Heteroskedasticity } \\
\text { II }\end{array}$ \\
\hline & & & \multicolumn{3}{|c|}{ Estimates } \\
\hline Constant & Intercept term & & $\begin{array}{l}-426.77 \\
(-6.994)\end{array}$ & $\begin{array}{l}-506.77 \\
(-2.652)\end{array}$ & $\begin{array}{l}-435.98 \\
(-2.459)\end{array}$ \\
\hline EXISTIMP & $\begin{array}{l}\text { Measure of importance of } \\
\text { wildlife existence }(1=\text { not } \\
\text { imp., } 5=\text { extremely imp.) }\end{array}$ & $\begin{array}{c}3.52 \\
{[0.62]}\end{array}$ & $\begin{array}{c}158.25 \\
(10.882)\end{array}$ & $\begin{array}{l}180.42 \\
(3.418)\end{array}$ & $\begin{array}{l}164.00 \\
(3.276)\end{array}$ \\
\hline INCOME & $\begin{array}{l}\text { Household income in } \\
\text { thousands of dollars }\end{array}$ & $\begin{array}{c}50.30 \\
{[33.16]}\end{array}$ & $\begin{array}{l}.00132 \\
(2.300)\end{array}$ & $\begin{array}{l}.00117 \\
(1.849)\end{array}$ & $\begin{array}{l}.00082 \\
(1.543)\end{array}$ \\
\hline TKNOW & $\begin{array}{l}\text { Dummy for knowledge of } \\
\text { habitat and wetlands } \\
\text { problems in San Joaquin } \\
\text { Valley }\end{array}$ & $\begin{array}{c}0.36 \\
{[0.48]}\end{array}$ & $\begin{array}{l}161.54 \\
(3.525)\end{array}$ & $\begin{array}{l}136.76 \\
(2.389)\end{array}$ & $\begin{array}{l}131.07 \\
(2.521)\end{array}$ \\
\hline$\sigma_{\nu}$ & $\begin{array}{l}\text { Standard deviation of } \\
\text { permanent component of } \\
\text { error }\end{array}$ & & $\begin{array}{l}217.29 \\
(6.210)\end{array}$ & $\begin{array}{l}178.08 \\
(4.405)\end{array}$ & $\begin{array}{l}160.39 \\
(4.498)\end{array}$ \\
\hline$\alpha_{0}$ & $\begin{array}{l}\text { Log standard deviation of } \\
\text { transitory component of } \\
\text { error }\end{array}$ & & $\begin{array}{c}5.83 \\
(30.733)\end{array}$ & $\begin{array}{c}5.46 \\
(14.140)\end{array}$ & $\begin{array}{c}5.32 \\
(14.34)\end{array}$ \\
\hline$\alpha_{11}$ & $\begin{array}{l}\text { Coefficient of squared bid } \\
\text { distance in first equation }\end{array}$ & & & $\begin{array}{l}4.9 \times 10^{-6} \\
(1.236)\end{array}$ & $\begin{array}{l}4.3 \times 10^{-6} \\
(1.150)\end{array}$ \\
\hline$\alpha_{12}$ & $\begin{array}{l}\text { Coefficient of squared bid } \\
\text { distance in second } \\
\text { equation }\end{array}$ & & & & $\begin{array}{c}1.17 \times 10^{-5} \\
(1.295)\end{array}$ \\
\hline$n$ & & & 516 & 516 & 516 \\
\hline $\log L$ & Log likelihood function & & -681.55 & -680.16 & -678.53 \\
\hline
\end{tabular}

Notes: Standard deviations are in brackets; $t$-statistics are in parentheses. 
TABLE 5

Heteroskedastic Random-efFect Model: Alaska Oil Spill CV SuRVey

\begin{tabular}{lccc}
\hline \hline $\begin{array}{l}\text { Variable/ } \\
\text { Parameter }\end{array}$ & $\begin{array}{c}\text { Basic Error-Component } \\
\text { Model }\end{array}$ & $\begin{array}{c}\text { Error-Component with } \\
\text { Heteroskedasticity I }\end{array}$ & $\begin{array}{c}\text { Error-Component with } \\
\text { Heteroskedasticity II }\end{array}$ \\
\hline$\mu$ & 3.0754 & 2.7748 & 2.6287 \\
& $(21.21)$ & $(18.68)$ & $(16.99)$ \\
$\sigma_{v}$ & 2.9888 & 3.2574 & 5.6656 \\
& $(8.72)$ & $(7.65)$ & $(4.57)$ \\
$\alpha_{0}$ & 0.7071 & 0.3876 & 0.8514 \\
& $(3.75)$ & $(1.63)$ & $(2.97)$ \\
$\alpha_{11}$ & & 0.2720 & -0.0450 \\
$\alpha_{12}$ & & $(3.32)$ & $(-0.64)$ \\
$n$ & & & 0.5315 \\
$\log L$ & 1,043 & 1,043 & $(4.583)$ \\
\hline
\end{tabular}

Note: $t$-statistics are in parentheses.

TABLE 6

Heteroskedastic Random-efFect Model with Covariates: KaKadu Conservation Zone CV SURVEY ("MINOR IMPACT" SCENARIO ONLY)

\begin{tabular}{|c|c|c|c|c|c|}
\hline \multirow{2}{*}{$\begin{array}{l}\text { Variable/ } \\
\text { Parameter }\end{array}$} & \multirow[b]{2}{*}{ Description of Variable } & \multirow{2}{*}{$\begin{array}{c}\text { Sample } \\
\text { Mean }\end{array}$} & $\begin{array}{l}\text { Basic Error- } \\
\text { Component } \\
\text { Model }\end{array}$ & $\begin{array}{l}\text { Error-Component } \\
\text { Model with } \\
\text { Heteroskedasticity } \\
\text { I }\end{array}$ & $\begin{array}{c}\text { Error-Component } \\
\text { Model with } \\
\text { Heteroskedasticity } \\
\text { II }\end{array}$ \\
\hline & & & \multicolumn{3}{|c|}{ Estimates } \\
\hline Constant & Intercept term & & $\begin{array}{l}684.35 \\
(6.20)\end{array}$ & $\begin{array}{l}686.82 \\
(6.30)\end{array}$ & $\begin{array}{l}675.23 \\
(5.17)\end{array}$ \\
\hline VPARKS & $\begin{array}{l}\text { Dummy for whether } \\
\text { respondent visited a National } \\
\text { Park in the last } 12 \text { months }\end{array}$ & $\begin{array}{c}0.75 \\
{[0.43]}\end{array}$ & $\begin{array}{l}79.72 \\
(2.36)\end{array}$ & $\begin{array}{l}79.95 \\
(2.40)\end{array}$ & $\begin{array}{l}85.22 \\
(2.53)\end{array}$ \\
\hline ENVCON & $\begin{array}{l}\text { Dummy indicator of an } \\
\text { environmentally friendly } \\
\text { respondent }\end{array}$ & $\begin{array}{c}0.50 \\
{[0.50]}\end{array}$ & $\begin{array}{l}57.82 \\
(2.00)\end{array}$ & $\begin{array}{l}57.83 \\
(2.07)\end{array}$ & $\begin{array}{l}60.21 \\
(2.01)\end{array}$ \\
\hline Q11 & $\begin{array}{l}\text { Measure of importance of jobs } \\
\text { when making decisions about } \\
\text { natural resources } \\
(1=\text { not important, } \\
5=\text { extremely important })\end{array}$ & $\begin{array}{c}2.72 \\
{[1.33]}\end{array}$ & $\begin{array}{l}-90.81 \\
(-4.98)\end{array}$ & $\begin{array}{l}-91.21 \\
(-5.10)\end{array}$ & $\begin{array}{l}-89.78 \\
(-4.40)\end{array}$ \\
\hline Q12 & $\begin{array}{l}\text { Measure of acceptance of low- } \\
\text { risk development activities } \\
\text { from mining } \\
(1=\text { not important, } \\
5=\text { extremely important })\end{array}$ & $\begin{array}{c}2.95 \\
{[1.43]}\end{array}$ & $\begin{array}{l}-150.81 \\
(-5.70)\end{array}$ & $\begin{array}{l}-151.51 \\
(-5.85)\end{array}$ & $\begin{array}{l}-150.01 \\
(-4.97)\end{array}$ \\
\hline$\sigma_{v}$ & $\begin{array}{l}\text { Standard deviation of } \\
\text { permanent component } \\
\text { of error }\end{array}$ & & $\begin{array}{l}323.96 \\
(6.13)\end{array}$ & $\begin{array}{l}326.64 \\
(6.29)\end{array}$ & $\begin{array}{l}318.62 \\
(4.93)\end{array}$ \\
\hline$\alpha_{0}$ & $\begin{array}{l}\text { Log standard deviation of } \\
\text { transitory component } \\
\text { of error }\end{array}$ & & $\begin{array}{c}4.54 \\
(18.38)\end{array}$ & $\begin{array}{c}4.57 \\
(17.44)\end{array}$ & $\begin{array}{c}4.54 \\
(11.00)\end{array}$ \\
\hline$\alpha_{11}$ & $\begin{array}{l}\text { Coefficient of squared bid } \\
\text { distance in first equation }\end{array}$ & & & $\begin{array}{l}-4.1 \times 10^{-7} \\
(-0.279)\end{array}$ & $\begin{array}{c}-3.79 \times 10^{-6} \\
(-0.86)\end{array}$ \\
\hline$\alpha_{12}$ & $\begin{array}{l}\text { Coefficient of squared bid } \\
\text { distance in second equation }\end{array}$ & & & & $\begin{array}{l}1.81 \times 10^{-6} \\
(0.82)\end{array}$ \\
\hline $\begin{array}{l}n \\
\log L\end{array}$ & Log likelihood function & & $\begin{array}{c}1,088 \\
-927.63\end{array}$ & $\begin{array}{c}1,088 \\
-927.60\end{array}$ & $\begin{array}{c}1,088 \\
-925.53\end{array}$ \\
\hline
\end{tabular}

Note: Standard deviations are in brackets; $t$-statistics are in parentheses. 
insignificant coefficients on cost distance. So, in this case, even though the transitory component of the variance is large, we are unable to explain any of it using our hypotheses. ${ }^{14}$ Estimation of the same model without covariates (not reported here) found a positive, significant coefficient on the cost distance in the second question. This result indicates that in some cases, heteroskedasticity might be resolved simply by adding relevant covariates to the model.

Table 5 reports estimation results for the same three models using the data from the Alaska survey. In this case, we obtain an estimate of the standard deviation of the permanent component of log WTP of 2.99 and that of the transitory component of $\exp (.7071)=2.028$. When heteroskedasticity is incorporated, we obtain a positive and insignificant estimate of $\alpha_{1}$. But when the effect of the cost distance is allowed to vary, a positive, significant coefficient is obtained for the second question only. This lends support for our second hypothesis that excessively high or low cost amounts increase variance. ${ }^{15}$

Finally, Table 6 reports estimation results from the Kakadu data. The basic error-component model obtains estimates of the standard deviation of the permanent component of 324.0 and of the transitory component of $\exp (4.54)=93.7$. The error-component model with heteroskedasticity obtains a negative but insignificant estimate of the coefficient on cost distance for the first question and a positive but insignificant estimate for the second question. This result is not surprising considering that the transitory component of the variance is already very small relative to the permanent component which leaves very little potential for explanation by structural heteroskedasticity. ${ }^{16}$

\section{Combining Random Effects, Systematic Shift and Heteroskedasticity}

The previous two sections have found that only the Alaska contingent valuation data demonstrates a systematic shift in WTP amounts and heteroskedasticity. We therefore present the fully specified model for the Alaska data in Table 7.
TABLE 7

SySTEMATIC ShIFT /HeTEROSKEDASTIC ERROR-COMPONENT MODEL: ALASKA CV SURVEY

\begin{tabular}{lc}
\hline \hline Parameter & $\begin{array}{c}\text { Error-Component with } \\
\text { Heteroskedasticity II } \\
\text { plus Shift }\end{array}$ \\
\hline$\mu$ & 3.7714 \\
$\delta$ & $(30.15)$ \\
$\sigma_{v}$ & -1.4722 \\
$\alpha_{0}$ & $(-5.48)$ \\
$\alpha_{11}$ & 3.2428 \\
$\alpha_{12}$ & $(8.26)$ \\
$n$ & 0.8231 \\
$\log L$ & $(3.91)$ \\
& -0.8417 \\
& $(-1.54)$ \\
& 0.0927 \\
& $(1.25)$ \\
& 1,043 \\
& $-1,300.71$ \\
\hline
\end{tabular}

Note: $t$-statistic in parentheses.

The full model is a significant improvement over the two previously estimated models in terms of the log-likelihood value obtained. A systematic shift is still evident but heteroskedasticity is insignificant, whereas in the model that does not account for the shift, significant heteroskedasticity is evident in the second question. It is clear in this case that if the model is not fully speci-

\footnotetext{
${ }^{14}$ Based on the basic error component specification, the cost differences for the initial payment questions ranged between -403.02 and 504.02 dollars, its average was $\$ 122$, and its standard deviation was $\$ 155.69$. The cost differences for the follow-up questions ranged between -561 and 534 dollars, with a mean of $\$ 101$, and a standard deviation of $\$ 152.50$.

${ }^{15}$ The cost distances based on the log of the initial cost amounts ranged between -0.3611 and 0.2580 , with an average of -0.0521 and a standard deviation of 0.2761 . The cost distances based on the $\log$ of the follow-up cost amounts ranged between -0.4318 and 0.0841 , with a mean of -0.1736 and a standard deviation of 0.1975 .

${ }^{16}$ The cost differences for the initial cost amounts ranged from -565.93 to 575.27 , with a mean of $\$ 48.77$ and a standard deviation of 301.85 . The cost differences for the follow-up cost amounts ranged between -636.21 and 578.27 , with a mean of $\$ 32.75$ and a standard deviation of $\$ 285.29$.
} 
fied, the researcher might come to false conclusions about the effects of the cost amounts on response behavior.

Our experiments with the Alaska data demonstrate an important lesson: the addition of parameters can sometimes improve the fit of a model even if the model specification is inappropriate. Researchers must be careful to avoid falsely interpreting significant parameter estimates as support for a particular response effect hypothesis. Ultimately, the decision as to which model specification is most appropriate should be based on the researcher's judgment about the possible incentives generated by the particular CV survey instrument being analyzed.

\section{CONCLUDING COMMENTS}

This paper has presented a systematic framework for exploring potential response incentives that may occur with dichotomous choice CV survey with follow-up questions. We generated structural adaptations to the standard CV model to investigate the possibilities of random response shocks, structural shifts in WTP and heteroskedasticity between and within responses. We emphasize that our hypotheses about response incentives are meant to be exploratory, rather than definitive. We hope that researchers will use the ideas presented in this paper to search for new approaches to modeling CV responses.

In this endeavor, we cannot emphasize enough the importance of developing a comprehensive theoretical framework to help understand how the incentives faced by survey participants and information available to them should influence response behavior (Carson, Groves, and Machina 1995). It is also important to use and further develop innovative survey techniques to debrief respondents about their perceptions at various points during the interview. Only by learning more about how respondents actually respond to various types of of WTP questions will we be able to improve our ability to model responses to those questions.

\section{References}

Alberini, A. 1995a. "Optimal Designs for Discrete Choice Contingent Valuation Surveys: Single-Bound, Double-bound, and Bivariate Models." Journal of Environmental Economics and Management 28 (2):287-306.

1995b. "Efficiency vs Bias of Willingnessto-Pay Estimates: Bivariate and Interval Data Models." Journal of Environmental Economics and Management 29 (2):169-80.

Bateman, I., and K. Willis, eds. Forthcoming. Contingent Valuation of Environmental Preferences: Assessing Theory and Practice in the USA, Europe and Developing Countries. Oxford: Oxford University Press.

Cameron, T. A. 1988. "A New Paradigm for Valuing Non-Market Goods Using Referendum Data: Maximum Likelihood Estimation by Censored Logistic Regression.” Journal of Environmental Economics and Management 15 (3):355-79.

Cameron, T. A., and J. Quiggin. 1994. "Estimation Using Contingent Valuation Data from a 'Dichotomous Choice with Follow-up' Questionnaire." Journal of Environmental Economics and Management 27 (3):218-34.

Carson, R. T., T. Groves, and M. Machina. 1995. "Comparative Statics of Approaches to Eliciting Economic Values." NSF/EPA Partnership Grant Proposal, Department of Economics, University of California, San Diego.

Carson, R. T., W. M. Hanemann, and R. C. Mitchell. 1986. "Determining the Demand for Public Goods by Simulating Referendums at Different Tax Prices." Department of Economics, University of California, San Diego.

Carson, R. T., R. C. Mitchell, W. M. Hanemann, R. J. Kopp, S. Presser, and P. A. Ruud. 1992. A Contingent Valuation Study of Lost Passive Use Values Resulting from the Exxon Valdez Oil Spill. Report to the General Attorney of the State of Alaska.

Carson, R. T., L. Wilks, and D. Imber. 1994. "Valuing the Preservation of Australia's Kakadu Conservation Zone." Oxford Economic Papers 46:727-49.

Chamberlain, G. 1980. "Analysis of Covariance with Qualitative Data." Review of Economic Studies 47:225-38.

Collett, D. 1991. Modelling Binary Data. London: Chapman and Hall.

Cox, D. R., and E. J. Snell. 1989. Analysis of Binary Data. 2nd ed. London: Chapman and Hall. 
Farmheir, L., and G. Tutz. 1994. Multivariate Statistical Modelling Based on Generalized Linear Models. New York: Springer-Verlag.

Gourieroux, C. 1984. Econometrie des Variables Qualitatives. Paris: Economica.

Hanemann, W. M. 1984. "Welfare Evaluations in Contingent Valuation Experiments with Discrete Responses." American Journal of Agricultural Economics 66 (Aug.):332-41.

Hanemann, W. M., and B. J. Kanninen. Forthcoming. "The Statistical Analysis of Discrete Response CV Data." In Contingent Valuation of Environmental Preferences: Assessing Theory and Practice in the USA, Europe and Developing Countries, ed. I. Bateman and K. Willis. Oxford: Oxford University Press.

Hanemann, W. M., J. B. Loomis, and B. J. Kanninen. 1991. "Statistical Efficiency of DoubleBounded Dichotomous Choice Contingent Valuation." American Journal of Agricultural Economics 73 (Nov.):1255-63.

Herriges, J. A., and Shogren, J. F. 1996. "Starting Point Bias in Dichotomous Choice Valuation with Follow-up Questioning," Journal of Environmental Economics and Management 30 (1):112-31.

Kanninen, B. J. 1995. "Bias in Discrete Response Contingent Valuation." Journal of Environmental Economics and Management 28 (1): 114-25.

Hsiao, C. 1986. Analysis of Panel Data. New York: Cambridge University Press.

Langford, I. 1994. "Using a Generalized Linear
Mixed Model to Analyze Dichotomous Choice Contingent Valuation Data." Land Economics 70 (Nov.):507-14.

Maddala, G. S. 1983. Limited-Dependent and Qualitative Variables in Econometrics. New York: Cambridge University Press.

McConnell, K. E. 1990. "Models for Referendum Data: The Structure of Discrete Choice Models for Contingent Valuation. Journal of Environmental Economics and Management 18 (1): 19-34.

Mitchell, R. C., and R. T. Carson. 1989. Using Surveys to Value Public Goods: The Contingent Valuation Method. Washington, DC: Resources for the Future.

Opaluch, J., and K. Segerson. 1989. "Rational Roots of 'Irrational' Behavior: New Theories of Economic Decision-making." Northeastern Journal of Agricultural Economics 18:81-95.

Poe, G. L., M. P. Welsh, and P. A. Champ. 1997. "Measuring the Differences in Mean Willingness to Pay When Dichotomous Choice Contingent Valuation Responses Are Not Independent." Land Economics 73 (May):255-67.

Ready, R., J. C. Whitehead, and G. C. Blomquist. 1995. "Contingent Valuation When Respondents are Ambivalent." Journal of Environmental Economics and Management 29 (2): 181-96.

Williams, D. A. 1982. "Extra-binomial Variation in Logistic Linear Models." Applied Statistics 31 (2):144-48. 
http://www.jstor.org

\title{
LINKED CITATIONS
}

- Page 1 of 2 -

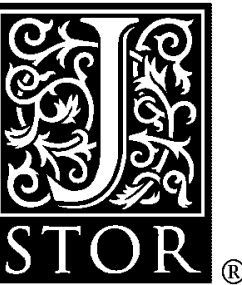

You have printed the following article:

Modeling Response Incentive Effects in Dichotomous Choice Contingent Valuation Data Anna Alberini; Barbara Kanninen; Richard T. Carson

Land Economics, Vol. 73, No. 3. (Aug., 1997), pp. 309-324.

Stable URL:

http://links.jstor.org/sici?sici=0023-7639\%28199708\%2973\%3A3\%3C309\%3AMRIEID\%3E2.0.CO\%3B2-2

This article references the following linked citations. If you are trying to access articles from an off-campus location, you may be required to first logon via your library web site to access JSTOR. Please visit your library's website or contact a librarian to learn about options for remote access to JSTOR.

\section{References}

\author{
Valuing the Preservation of Australia's Kakadu Conservation Zone \\ Richard T. Carson; Leanne Wilks; David Imber \\ Oxford Economic Papers, New Series, Vol. 46, Special Issue on Environmental Economics. (Oct., \\ 1994), pp. 727-749. \\ Stable URL: \\ http://links.jstor.org/sici?sici=0030-7653\%28199410\%292\%3A46\%3C727\%3AVTPOAK\%3E2.0.CO\%3B2-7
}

\author{
Analysis of Covariance with Qualitative Data \\ Gary Chamberlain \\ The Review of Economic Studies, Vol. 47, No. 1, Econometrics Issue. (Jan., 1980), pp. 225-238. \\ Stable URL: \\ http://links.jstor.org/sici?sici=0034-6527\%28198001\%2947\%3A1\%3C225\%3AAOCWQD\%3E2.0.CO\%3B2-L
}

\author{
Welfare Evaluations in Contingent Valuation Experiments with Discrete Responses \\ W. Michael Hanemann \\ American Journal of Agricultural Economics, Vol. 66, No. 3. (Aug., 1984), pp. 332-341. \\ Stable URL: \\ http://links.jstor.org/sici?sici=0002-9092\%28198408\%2966\%3A3\%3C332\%3AWEICVE\%3E2.0.CO\%3B2-N
}

\author{
Statistical Efficiency of Double-Bounded Dichotomous Choice Contingent Valuation \\ Michael Hanemann; John Loomis; Barbara Kanninen \\ American Journal of Agricultural Economics, Vol. 73, No. 4. (Nov., 1991), pp. 1255-1263. \\ Stable URL: \\ http://links.jstor.org/sici?sici=0002-9092\%28199111\%2973\%3A4\%3C1255\%3ASEODDC\%3E2.0.CO\%3B2-I
}


http://www.jstor.org

\section{LINKED CITATIONS \\ - Page 2 of 2 -}

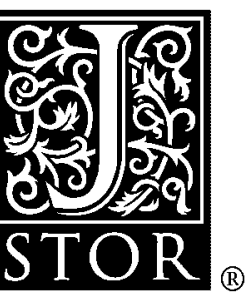

Using a Generalized Linear Mixed Model to Analyze Dichotomous Choice Contingent Valuation Data

Ian H. Langford

Land Economics, Vol. 70, No. 4. (Nov., 1994), pp. 507-514.

Stable URL:

http://links.jstor.org/sici?sici=0023-7639\%28199411\%2970\%3A4\%3C507\%3AUAGLMM\%3E2.0.CO\%3B2-Q

Measuring the Difference in Mean Willingness to Pay When Dichotomous Choice Contingent Valuation Responses Are Not Independent

Gregory L. Poe; Michael P. Welsh; Patricia A. Champ

Land Economics, Vol. 73, No. 2. (May, 1997), pp. 255-267.

Stable URL:

http://links.jstor.org/sici?sici=0023-7639\%28199705\%2973\%3A2\%3C255\%3AMTDIMW\%3E2.0.CO\%3B2-2

\section{Extra-Binomial Variation in Logistic Linear Models}

D. A. Williams

Applied Statistics, Vol. 31, No. 2. (1982), pp. 144-148.

Stable URL:

http://links.jstor.org/sici?sici=0035-9254\%281982\%2931\%3A2\%3C144\%3AEVILLM\%3E2.0.CO\%3B2-O 